\title{
DA PÁGINA EM BRANCO ÀS \\ PRIMEIRAS IMPRESSÕES DE UMA \\ GEOGRAFIA CULTURAL BRASILEIRA
}

- LENICE LIRA ${ }^{1}$

1 Doutora em Geografia pela Universidade Federal do Rio de Janeiro; professora da rede pública do Estado do Rio de Janeiro (SEEDUC); pesquisadora independente. E-mail para contato: lenice_lira@yahoo.com.br

Recebido em: $10 / 07 / 2020$

Aprovado em: 22/01/2021

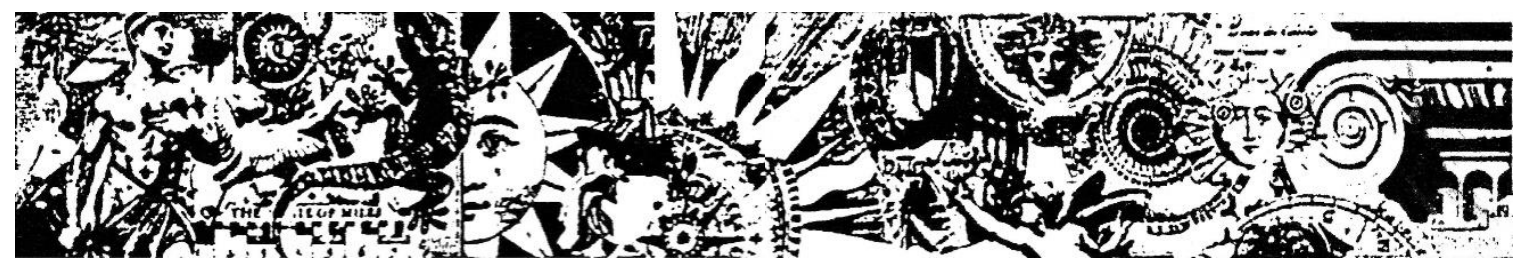

A revista Espaço e Cultura, ao longo de sua existência, constitui um espaço de debate e difusão de reflexões sobre diferentes temas e realidades no âmbito da geografia cultural. Segundo Augustin Berque (1984), a geografia cultural é entendida como o "estudo do sentido (global e unitário) que uma sociedade atribui à sua relação com o espaço e com a natureza: relação que a paisagem exprime concretamente" (BERQUE, 1984) ${ }^{2}$. A busca pelo sentido anima as pesquisas na geografia cultural. Enunciar uma realidade significa enunciar um modo de existir. Desse modo, podemos afirmar que a Espaço e Cultura criou as condições de existência de uma geografia cultural no Brasil e de seu reconhecimento na comunidade científica internacional.

O periódico se destaca principalmente por seu caráter inovador e pioneiro nas discussões no âmbito da geografia humana e cultural.

${ }^{2}$ Conferir Augustin Berque, Paysage-empreinte, paysage-matrice : éléments de problématique pour une géographie culturelle. L'Espace Géographique, 1984, 13 (1), pp. 33-34. 


\section{7:}

A criação da Revista, em 1995, pelo Núcleo de Pesquisas sobre Espaço e Cultura (NEPEC) - coordenado por Zeny Rosendahl, acontece no contexto de renovação da Geografia Cultural, caracterizada pela emergência de novos temas de pesquisa, como as representações sociais, a expressões artísticas, a paisagem e a religiosidade, revelando a importância da dimensão simbólica da realidade, que não pode mais ser pensada sob a tutela do paradigma moderno. Os aspectos materiais e simbólicos da realidade são indissociáveis na compreensão dos fenômenos e questões emergentes no mundo contemporâneo e pretérito.

O periódico tem ainda estimulado novos diálogos e encontros entre diferentes saberes; além de divulgar novas abordagens teóricas, epistemológicas, metodológicas e práticas sobre um vasto leque de temas, o que tem sido fundamental para o avanço de uma geografia cultural no Brasil e no mundo. Desde então a revista continua a nos surpreender com as temáticas propostas em suas edições. Essa característica modificou a evolução dos estudos culturais na geografia brasileira e abriu o campo para novas reflexões e debates sobre a dimensão cultural do espaço.

Num determinado período, tive o privilégio e a alegria de participar da trajetória desse periódico, que, por sua vez, contribuiu para minha formação enquanto geógrafa e pesquisadora. Esta experiência me permitiu reconhecer o caráter formador e a importância das publicações da revista na construção do acesso a um mundo até então pouco visitado e explorado pela comunidade científica brasileira. Recordo-me das primeiras edições da revista: matrizes da Geografia Cultural, paisagem, religião; que maravilhamento diante de textos inéditos e da possibilidade de diálogo e debates sobre novos temas, em um período em que a tradução dos textos culturais era quase inexistente no idioma português.

A ousadia e a liberdade das temáticas discutidas nos Simpósios sobre Espaço e Cultura, organizados pelo NEPEC, e divulgadas na revista, produziam uma atmosfera de pertencimento e lugar no mundo. Ali se podia pensar e refletir sobre novos temas, como o da paisagem e as suas representações, no contexto da geografia no Brasil. Mas o caminho se traçava ao caminhar, como dizia o poeta Antonio Machado.

E como já foi dito por Mariana Lamego e André Reyes Novaes (2109), a revista constitui "um espaço de produção, circulação e recepção de ideias e imagens sobre as abordagens culturais na geografia..." ${ }^{3}$, colocando em evidência o que é por natureza e o que é por convenção. Os artigos publicados na revista permitiram

\footnotetext{
${ }^{3}$ Conferir o prefácio da Revista Espaço e Cultura, n.46, jul/dez 2019, p. 9. 


\section{8:}

aprofundar e desenvolver um rico debate teórico, conceitual e metodológico sobre questões estéticas e espaciais que estão ligadas à elaboração de formas distintas de paisagens, de diferentes formas de apropriação do território e de vivências do lugar.

O legado do periódico Espaço e Cultura é enorme! Um projeto bem sucedido, concebido pela geógrafa e pesquisadora Zeny Rosendahl e pelo geógrafo e pesquisador Roberto Lobato Corrêa - fundadores visionários, sem dúvidas. Esses geógrafos colocaram em evidência o papel ativo da cultura na produção de espacialidades, cujo conteúdo da revista continua a enriquecer, estimular e inspirar os estudos culturais.

Os 25 anos de existência através das publicações do periódico Espaço e Cultura e a realização dos Simpósios Nacionais e internacionais favoreceram o debate acerca das possibilidades e limites metodológicos no processo de conhecimento geográfico de uma realidade específica, o que permitiu delimitar alguns percursos metodológicos empreendidos pela geografia nas interpretações de obras de arte e representações sociais; bem como esclarecer o modo como as representações visuais engendram processos de transposição, transformação, informação e comunicação de significados de mundos, que envolvem a materialidade e o seu conteúdo simbólico, além de participarem da constituição da realidade, pois a presença dos objetos ou coisas no espaço afeta os indivíduos e coletividades nas quais estão inseridos, desencadeando novas sensibilidades e configurações espaciais. Estas, por sua vez, modificam a experiência de tempo e de espaço, logo produzem novos modos de se organizar em sociedade.

Por fim, ressalto que a consolidação da abordagem cultural na geografia foi forjada pelo trabalho incansável do NEPEC para alcançar uma maturidade e reconhecimento legítimos. 


\section{9:}

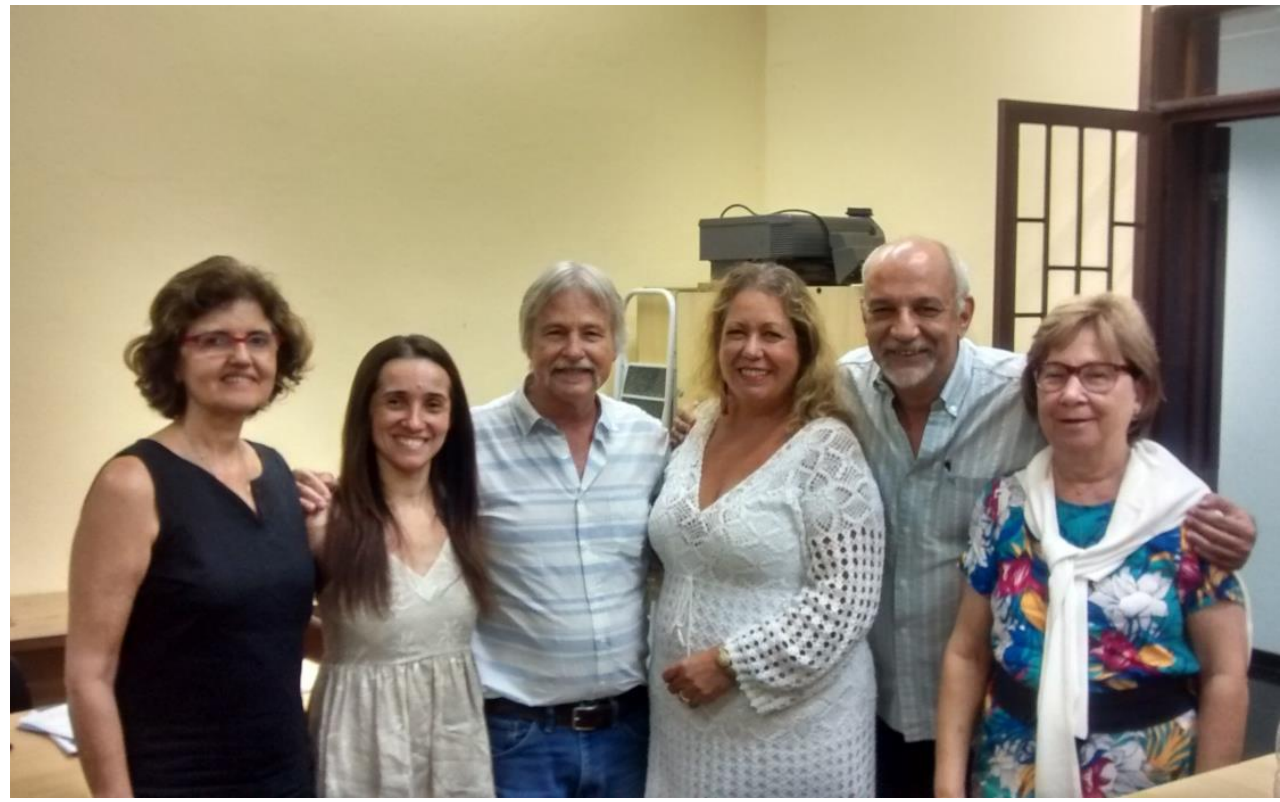

Figura 1: Encontro de pesquisadoras(es) da geografia cultural (Universidade Federal do Rio de Janeiro) Fonte: Jefferson de Oliveira, 2017).

\section{REFERÊNCIAS BIBLIOGRÁFICAS}

BERQUE, A. Paysage-empreinte, paysage-matrice : éléments de problématique pour une géographie culturelle. L'Espace Géographique, 1984, 13 (1), pp. 33-34.

CORREAA, R. L; ROSENDAHL, Zeny (org.). Introdução à geografia cultural. Rio de Janeiro: Bertrand Brasil, 2003.

COSGROVE, D. Worlds of meaning: Cultural Geography and the imagination. In: FOOTE, Kenneth E. Re-reading the Cultural Geography. Austin: University of Texas, pp. 387-395, 1994.

DIDI-HUBERMAN, G. Devant l'image: question posée aux fins d'une histoire de l'art. Paris : Les Éditions de Minuit, 1990.

ESPAÇO E CULTURA. Rio de Janeiro: UERJ/NEPEC, n. 40, jul/dez 2019.

MACHADO, Antonio. Campos de Castilla. Madri: Editorial Literanda, 2012. 